\title{
Do 12-Week Yoga Program Influence Respiratory Function of Elderly Women?
}

\author{
by \\ Lídia Aguiar Bezerra ${ }^{1}$, Helton Fabrício de Melo ${ }^{1}$, Ana Paula Garay ${ }^{1}$, Victor Machado \\ Reis 2,3, Felipe José Aidar 2,3,4, Ana Rita Bodas ${ }^{2,3}$, Nuno Domingos Garrido ${ }^{2,3}$, Ricardo \\ Jacó de Oliveira ${ }^{1}$
}

Aging produces several respiratory limitations and reduces tolerance to physical efforts, sometimes leading to pulmonary diseases in the elderly. The literature draws attention to the possible benefits of Yoga practice among the elderly, presenting evidence for significant improvements in quality of life. It was hypothesized that yoga practice can improve respiratory function in the elderly. The effects of a yoga program on pulmonary volumes and respiratory muscle strength were verified in 36 elderly women divided into a yoga group [YG] (63.1 \pm 13.3 years of age) and a control group (61.0 \pm 6.9 years of age). Maximal inspiratory and expiratory pressure (MIP and MEP) were assessed by a manovacuometer and tidal volume (VT), vital capacity $(V C)$ and minute ventilation (VE) were measured by a ventilometer. The program comprised 65 min sessions, 3 times/week during 12 weeks. The heart rate and respiratory rate decreased significantly in the $Y G(76-39 \pm 8-03 \mathrm{vs} .74-61 \pm 10.26 \mathrm{bpm}$ and $18.61 \pm 3.15 \mathrm{vs} .16 .72 \pm 3.12 \mathrm{resp} / \mathrm{min}$, respectively). In the $Y G, V T$ and VE increased significantly $(0.55 \pm 0.22$ vs. $0.64 \pm 0.2 \mathrm{ml}$ and $9.19 \pm 2.39 \mathrm{vs} .10 .05 \pm$ $2.11 \mathrm{ml}$, respectively), as well as VC (1.48 $\pm 0.45 \mathrm{vs} .2 .03 \pm 0.72 \mathrm{ml})$. Improvements were also found in MIP and MEP in the YG (62.17 \pm 14.77 vs. $73.06 \pm 20.16 \mathrm{cmH} 2 \mathrm{O}$ and $80.56 \pm 23.94$ vs. $86.39 \pm 20.16 \mathrm{cmH} 2 \mathrm{O}$, respectively). It was concluded that a 12-week yoga program significantly improves pulmonary function of aged women.

Key words: elderly, women, respiratory strength, respiratory volumes, yoga.

\section{Introduction}

Aging produces several respiratory limitations and reduces tolerance to physical efforts, sometimes leading to pulmonary diseases in the elderly (Grinton, 1994; Turcic et al., 2002; Marek et al., 2011). More specifically, aging promotes the reduction of respiratory function (namely pulmonary volumes and respiratory muscle strength) due to gradual loss of pulmonary spring and to reduction of the alveolar area, at the rate of $4 \%$ per decade after the age of 30 , as well as a reduction in movement amplitude of intervertebral joints (Rossi et al., 1996; Becklake et al., 1999).

Additionally, the aging process is associated with muscle weakness and alterations in pulmonary parenchyma which in turn, affects the ability to generate a satisfactory airflow (Brito et al., 2009; Freitas et al., 2010).

According to Higgibothan et al. (1986) and Rode and Shephard (1994), the loss of pulmonary power together with physical inactivity cause a decrease in the use of peripheral

\footnotetext{
1 - University of Brasilia, Brasilia, Brazil.

2 - Department of Sport Sciences, University of Trás-os-Montes and Alto Douro, Vila Real, Portugal.

3 - Research Centre for Sport, Health and Human Development, Vila Real, Portugal.

4 - Fire Brigade of Minas Gerais, 5th Battalion Fire Military Fire Brigade of the State of Minas Gerais, New Horizons Program, Uberlandia, Minas Gerais, Brazil.
} 
oxygen. Moreover, physical inactivity is related with a decrease of the forced expiratory volume during the first second in men and women (47-74 years old), being a risk factor for cardiovascular diseases, thrombosis and lung cancer (Jakes et al., 2002). Muscle strength in inspiration also decreases both in men and women after 55 years old (Black et al., 1969). This effect may be a consequence of increased flexibility of the muscles responsible for inspiration, as previously observed (Teodori et al., 2003).

Physical exercises increase pulmonary capacity preventing its loss with aging (Babb et al., 1997; Delorey et al., 1999). In case of middleaged subjects, Pelkonen et al. (2003) showed that physical exercise delayed a decrease of pulmonary function and caused changes in forced vital capacity and other pulmonary volumes.

Among the different types of physical exercise, yoga is becoming more and more important in western civilizations. This is an Indian millenary technique which is aimed at flexibility, muscle strength and meditation, and it includes respiratory exercises which enhance pulmonary capacities (Gopal et al., 1973; Ray and Sinha, 2001; Bernardi et al., 2002; Manocha et al., 2002; Cooper et al., 2003; Mandanmoha et al., 2003). However, the majority of those studies analysed young adults and children, especially those suffering from asthma.

The literature draws attention to the possible benefits of Yoga practice among the elderly, presenting evidence for significant improvements in quality of life (Oken et al., 2006) and mental depression (Krishnamurthy and Telles, 2007). However, the literature is scarce on the effects of yoga exercises on ventilation capacities and respiratory muscle strength in the elderly in a shorter period of time (Vyas and Dikshit, 2002).

Therefore, this study tested the hypothesis that yoga practice can improve respiratory function in the elderly.

\section{Material and Methods}

\section{Subjects}

The sample comprised 36 women randomly divided into two groups of equal size $(n=18)$ : a yoga group (YG) with a mean age of 63.1 \pm 13.3 years and a control group (CG) with a mean age of $61.0 \pm 6.9$ years. All the volunteers were residing in Brasília, and surrounding areas of Distrito Federal and the recruitment procedure was performed at the convenience of the researcher. Only women over 55 years of age, not engaged in any type of physical exercise (including yoga) in the previous six months, presenting a functional teeth set and without former pulmonary disease were allowed to participate in the study. All subjects provided their written informed consent to participate in the experiment and the procedures were approved by the institutional Ethics Committee of the Catholic University of Brasília.

\section{Procedures}

The aim of the present study was to analyse the influence of a 12-week yoga program on pulmonary volumes and respiratory muscle strength in elderly women.

Before the start of the experiment, all women went to the Studies in Physical Exercise and Health Laboratory (Brasília Catholic University-Brazil) to discard any possible medical counter indication. Their resting peripheral oxygen saturation and cardiac frequency were assessed with a Nonin $^{\circledR}$ oximeter. Resting arterial blood pressure measurements were also executed with the use of a Becton Dickinson ${ }^{\circledR}$ sphygmomanometer and a Littmann ${ }^{\circledR}$ stethoscope. The subjects were submitted to the same measurements one week after the experiment due the laboratory date availability.

In the week prior to the experiment, respiratory muscle strength and pulmonary volume analyses were performed. Before those analyses each subject visited the laboratory for a general explanation of the assessment training protocol (Black and Hyatt, 1969; Volianitis et al., 2001). The subjects then underwent a 12-week yoga exercise program. The program was comprised of three sessions per week, with 65 minute duration of each session. One week after the conclusion of the program the same measurements were taken.

\section{Respiratory muscle strength assessment}

Maximum inspiration pressure (MIP) and maximum expiration pressure (MEP) were measured with an aneroid class B model manuvacuometer $\quad\left(\right.$ Support $\left.^{\circledR}\right)$, capable of measuring negative and positive pressures with a -160 to $+2 \mathrm{O}_{\mathrm{cmH}} \mathrm{O}$ range. The manuvacuometer 
was connected to a semi flexible cylindrical plastic tube (140 mm width and $25 \mathrm{~mm}$ in diameter) where a nozzle and a rigid plastic connector of 1 mm hole were fastened.

\section{Pulmonary volume assessment}

The tidal volume $\left(\mathrm{V}_{\mathrm{T}}\right)$, minute ventilation $\left(\mathrm{VE}_{\mathrm{E}}\right)$ and vital capacity $(\mathrm{VC})$ were assessed with a $70 \times 60 \mathrm{~mm}$ ventilometer (Wright Respirometer Mark 8) attached by a $22 \mathrm{~mm}$ connection to a semi flexible cylindrical plastic tube $(140 \mathrm{~mm}$ width and $25 \mathrm{~mm}$ in diameter) where a nozzle and a rigid plastic connector were fastened.

\section{Evaluation Protocol}

All measurements were performed by the same experienced technician. The volunteers remained seated, with a $90^{\circ}$ angle between the trunk and the thighs, feet relaxed and one of the arms resting on the thigh (Volianitis et al., 2001). During measurements, verbal encouragement was provided (Volianitis et al., 2001).

Firstly, respiratory volumes were assessed, followed by the MIP and MEP assessment (Clanton and Diaz, 1995).

To take MIP and MEP the participant put the tube against the face and obstructed the nose with a clip and adjusted the teeth to the nozzle which involved also the lips, so that no air escaped. The connector with a $1 \mathrm{~mm}$ hole was used to avoid the interference of facial muscles in pressure values (Clanton and Diaz, 1995; HarikKhan and Wise, 1998; Volianitis et al., 2001). For MIP measures, the participants were told to slowly and completely exhale the air till the residual volume, so that the maximum inspiration effort should be achieved (Black and Hyatt, 1969). For MEP, the subject inspired till the total pulmonary capacity. Then the subject executed a maximum expiratory effort against the closed tube (Black and Hyatt, 1969; Enright et al., 1994; Harik-Khan and Wise, 1998; Volianitis et al., 2001). Both manoeuvers were executed during 2 seconds. At least three trials were performed with two minutes of recovery between them. The highest obtained values were used in the analysis. A five minute rest period was applied between MIP and MEP measurements (Enright et al., 1994). The higher record of MIP and MEP was considered for each subject (Volianitis et al., 2001), as long as the difference between the highest record and the other measurements was less than
$10 \%$.

As for $\mathrm{V}_{\mathrm{E}}, \mathrm{V}_{\mathrm{T}}$ and slow vital $\mathrm{VC}$ assessment the volunteers put a nose clip, adjusted the nozzle to the teeth, and closed the lips so that no air escaped. At the end of each evaluation, the volumetric scale was adjusted to zero. Each participant was asked to breathe normally when taking the $\mathrm{V}_{\mathrm{T}}$ and rate (RR) values. Thus, the $\mathrm{V}_{\mathrm{T}}$ was calculated through the relationship between the $V_{E}$ and RF. For slow VC, the subject was asked to make a maximum inspiration and next slowly expire till residual volume.

\section{Heart Rate Assessment}

The heart rate (HR) was obtained by a Finger-Tip oximeter $\left(\mathrm{NONIN}^{\circledR}\right)$.

\section{Yoga program}

The yoga program for elderly people lasted 12 weeks and it was performed three times per week, 65 min per session with each yoga exercise session divided into 3 parts: preparatory, main and final (Luby, 1977). Each phase is described in detail below.

Preparatory phase: 5 min relaxing with nasal respiratory exercises and $5 \mathrm{~min}$ for a joint warm-up. During respiratory exercises the participants were sitting and performed the following exercises: i) Adhama Pranayama (deep breathes with or without air retention); ii) Kapalabhati (exhaling the air with vigour through the nostrils); iii) Nadi Sodhana (alternated breathing through the nostrils); iv) Bastrika (inhaling and exhaling as fast and strong as possible, producing a noise as loud as the sound of a sickle). Concomitantly with these respiratory exercises, techniques for abdominal muscles were also performed: Udyana Bhanda (contraction of the abdominal region breathing normally or after a forced exhalation) and Jalandhara Bandha (contraction of larynx muscles after an inhalation).

Main phase: $50 \mathrm{~min}$ to repeat 15 positions (asanas), with 15 to $20 \mathrm{~s}$ per each repetition. The positions were as follows: tree position (vrikasana), triangle position (triconasana), royal ballerina (natarajasana), hands on feet (padahastasana), wheel position (chakrasana), vertebral column torsion (vakrasana), incan position (pashimotanasana), snake position (bhujangasana), turtle position (kurmasana), cat position (katuspadasana), grasshopper position (salabhasana), head on the knees (janusirsharsana), arch position 
(danurasana), sail (sarvangasana) and the sickle (viparitakarani) (Luby, 1977).

Final phase: $10 \mathrm{~min}$ for final induced relaxation, with natural and spontaneous breathing through the nostrils with the individuals in dorsal decubitus and eyes closed.

\section{Statistical Analysis}

The results are presented as means and standard deviations. Comparisons between measures were performed with the Split-plot Anova after the normality assumption was confirmed. The significance threshold was set at $p \leq 0.05$.

\section{Results}

Morphological and resting physiological measurements are presented in Table 1. Initial values (pre) did not differ between the two groups. The heart rate decreased significantly in the yoga group $(p \leq 0.05)$ but not in the control group. The respiratory rate decreased significantly $(p \leq 0.05)$ in the Yoga group between pre and post tests.

Respiratory muscle strength and pulmonary volume measures are presented in Table 2. Initial values (pre) did not differ between the two groups. The yoga program induced significant changes in $\mathrm{VE}_{\mathrm{E}}, \mathrm{VC}, \mathrm{MIP}$ and $\operatorname{MEP}(p \leq$ 0.05). Post-training $\mathrm{VE}_{\mathrm{E}}$ and $\mathrm{VC}$ were higher in the experimental group when compared with the controls $(p \leq 0.05)$.

Table 1

Body mass, resting heart rate and resting respiratory rate before (Pre) and after (Post) the experiment. Values are expressed as means and standard deviations

\begin{tabular}{lcccc}
\hline & \multicolumn{2}{c}{ Yoga Group $(\mathbf{n}=\mathbf{1 8})$} & \multicolumn{2}{c}{ Control Group $(\mathbf{n}=18)$} \\
& Pre & Post & Pre & Post \\
& & & & \\
\hline Body mass $(\mathrm{kg})$ & $63.06 \pm 13.4$ & $63.11 \pm 12.8$ & $65.77 \pm 9.4$ & $67.58 \pm 10.6$ \\
& & & & \\
Heart rate (beat $\left.\cdot \mathrm{min}^{-1}\right)$ & $76.39 \pm 8.03$ & $74.61 \pm 10.26+$ & $77.28 \pm 11.9$ & $79.78 \pm$ \\
& & & & 12.09 \\
Respiratory rate $\left(\right.$ cycle $\left.\cdot \mathrm{min}^{-1}\right)$ & $18.61 \pm 3.15+$ & $16.72 \pm 3.12$ & $14.61 \pm 2.03$ & $15.61 \pm 2.59$
\end{tabular}

$t=$ significant difference between pre and post test in the $Y G(p \leq 0.05)$. 
Table 2

Means and standard deviations of Tidal volume $\left(V_{T}\right)$, minute ventilation $\left(V_{E}\right)$, vital capacity

$(V C)$, maximal inspiratory pressure (MIP) and maximal expiratory pressure

$(M E P)$ in the two groups before (pre) and after (post) the experiment

\begin{tabular}{lcccc}
\hline & \multicolumn{2}{c}{ Yoga Group $(\mathbf{n}=\mathbf{1 8})$} & \multicolumn{2}{c}{ Control Group $(\mathbf{n}=18)$} \\
& Pre & Post & Pre & Post \\
\hline $\mathrm{V}_{\mathrm{T}}(\mathrm{ml})$ & $0-55 \pm 0.22$ & $0.64 \pm 0.20 \S$ & $0.56 \pm 0.20$ & $0.56 \pm 0.11$ \\
$\mathrm{VE}(\mathrm{ml})$ & $9.19 \pm 2.39$ & $10.05 \pm 2.11+\S$ & $7.92 \pm 1.23$ & $7.76 \pm 1.09$ \\
$\mathrm{VC}(\mathrm{ml})$ & $1.48 \pm 0.45$ & $2.03 \pm 0.72+\S$ & $1.96 \pm 0.4$ & $1.90 \pm 0.43$ \\
$\mathrm{MIP}\left(\mathrm{cmH}_{2} \mathrm{O}\right)$ & $62.17 \pm 14.77$ & $73.06 \pm 20.16 \S$ & $70.94 \pm 15.07$ & $70.28 \pm 15$ \\
$\mathrm{MEP}\left(\mathrm{cmH}_{2} \mathrm{O}\right)$ & $80.56 \pm 23.94$ & $86.39 \pm 20.16 \S$ & $75.83 \pm 16.29$ & $74.12 \pm 16.02$ \\
\hline
\end{tabular}

$t=$ significant difference in Post between the $Y G$ and $C G(p \leq 0.05)$.

$\S=$ significant difference between Pre and Post in the $Y G(p \leq 0.05)$.

\section{Discussion}

This study tested the hypothesis that yoga practice can improve respiratory function in the elderly. The main finding of this study was that the subjects that were submitted to the yoga program achieved significant changes in their pulmonary volumes and respiratory muscle strength. Additionally, the resting heart rate and respiratory rate also decreased significantly after the 12-week program.

The significant decrease in the heart rate and respiratory rate in the experimental group occurred probably due to an increase of the parasympathetic activity. Indeed, this effect had been previously observed in young adults (Gopal et al., 1973) and in subjects whose age ranged from 20 to 46 years (Vempati and Telles, 2002). This possible mechanism of adaptation was also referred by Bernardi et al. (2002) who observed that baroreflex sensitivity could be reached through slow breathing. This effect may be possible for both healthy people and those suffering from chronic cardiac insufficiency.
Probably, the increase of vagal activity and the reduction of sympathetic activity may reduce the HR and RR observed during slow breathing, and it is associated with yoga breathing which substantially reduces the chemo reflex response to hypoxia, probably through the improved oxygen delivery to tissues (Aktar et al., 2013). Other references in the literature also provide data to support practice of yoga to promote a reduction of the HR and RR (Cebriá et al., 2013; Vyas and Dikshit, 2002). Moreover, other than the meditation and relaxation techniques, the subjects in the present study were submitted to a program which also included static positions that could be viewed as a physically demanding exercise. Therefore, the combination of these two elements together may justify the decrease in RF and CF.

In the yoga group, we also observed an increase in the VC, $\mathrm{V}_{\mathrm{E}}$ and $\mathrm{V}_{\mathrm{T}}$. In our opinion, these adaptations could be a result of the inclusion of pranayamas (respiratory technique) together with the asanas (static physical positions) in the yoga program. The pranayamas execution 
covers several percentiles of the total pulmonary capacity and it influences the action of the diaphragm by the quantity of the inhaled air. For instance, the sub maximum activation of the diaphragm within low pulmonary volumes, may be a consequence of the differences of the relation width-inspiration muscles tension and/ the inhibition reflex of the frenic moto neuron (McKenzie et al., 1996; Weiner et al., 2003). Additionally, the pranayamas also aims to address the relationship between the width-muscle tension (pre and post charge), the elastic pulmonary properties and the different time constants of pulmonary insufflations, as well as the regional difference of perfusion ventilation due to upright and horizontal positions. In our opinion, all these characteristics do indicate this exercise as a main candidate to explain the changes in the aforementioned variables.

In the present study, there was a significant increase in MIP and MEP after the yoga program. This effect may be an adaptation of the respiratory muscles to the breath training included in the program. The study carried out by Weiner et al. (2003) in elderly subjects suffering from chronic obstructive pulmonary disease provides evidence for this assumption. Those authors observed that the conditioning of abdominal muscles allowed the preservation of the width of the diaphragm muscles fibres and its ability to generate strength at the beginning of the contraction of inspiratory muscles, despite of the pulmonary hyperinflation. Some exercises of the yoga program matched the typical characteristics of respiratory muscle conditioning. This is the case of breath exercises that were adopted, such as Kapalabhati (sequence of forced exhalations) and Udiyana Bhandha (abdominal contraction after a forced exhalation), both performed with a static technique (to restrain contraction) and with a dynamic technique (several contractions with retention after the exhalation). Additionally, widening of inspiration musculature promotes the action of the expiratory muscle group which could justify the increase of MEP.

On the other hand, significant improvement of MIP, may have occurred due to the flexibility of the muscles responsible for inhalation, as previously observed (Teodori et al., 2003). Teodori et al.'s (2003) study investigated the use of global posture re-education (which included flexibility and respiratory exercises) and observed an improvement in the coordination of the action of that muscle group, probable due to the strength exertion required in the expiratory muscles during the execution of the appropriate posture.

\section{Conclusions}

We concluded that a 12-week practice of yoga significantly improved the pulmonary function of elderly women. To our knowledge, this was the first study to report such adaptations in a western population of this subject group. These results draw attention to the possible importance of yoga practice in the elderly as a preventive exercise to impair age-related morbidity and improve the quality of life of these populations.

\section{References}

Akhtar P, Yardi S, Akhtar M. Effects of Yoga on Functional Capacity and Well Being. Int J Yoga, 2013; 76-9

Babb TG, Long KA, Rodarte J. The Relationship Between Maximal Expiratory Flow and Increases of Maximal Exercise Capacity with Exercise Training. Am J Respir Crit Care Med, 1997; 156: 116-121

Becklake M, Kauffmann F. Gender Differences in Airway Behaviour Over The Human Life Span. Thorax, 1999; 54: 1119-1138

Bernardi L, Porta C, Spicuzza L, Bellwon J, Spadacini G, Frey AW, Yeung LY, Sanderson JE, Pedretti R, Tramarin R. Slow Breathing Increases Arterial Baroreflex Sensitivity in Patients With Chronic Heart Failure. Circulation, 2002; 105: 143-145

Black LF, Hyatt RE. Maximal respiratory pressures: normal values and relationship to age and sex. Am Rev Respir Dis, 1969; 99: 696-702

Brito R, Zampa C, Oliveira T, Prado L, Parreira V. Effects of the Aging Process on Respiratory Function. 
Gerontology, 2009; 55: 505-510

Cebrià i Iranzo MÀ, Arnall DA, Igual Camacho C, Tomás JM. Effects of inspiratory muscle training and yoga breathing exercises on respiratory muscle function in institutionalized frail older adults: a randomized controlled trial. J Geriatr Phys Ther, 2014; 37(2): 65-75

Clanton TL, Diaz PT. Clinical assessment of the respiratory muscle. Physical Therapy, 1995; 75(11): 983-985

Cooper S, Oborne J, Newton J, Harrison V, Coon JT, Lewis S, Tattersfield A. Effect of Two Breathing Exercise (Buteyko and Pranayama) in Asthma: A Randomised Controlled Trial. Thorax, 2003; 58: 674-679

Delorey DS, Babb TG. Progressive Mechanical Ventilatory Constraint with Aging. Am J Respir Crit Care Med, 1999; 160: 169-177

Enright PL, Kronmal RA, Manolio TA, Schencker MB, Hyatt RE. Respiratory muscle strength in the elderly. Am J Respir Crit Care Med, 1994; 149: 430-438

Freitas FS, Ibiapina CC, Alvim CG, Britto RR, Parreira VF. Relationship Between Cough Strength And Functional Level In Elderly. Rev Bras Fisioter, 2010; 14(6): 470-6

Gopal KS, Bhatnagar P, Subramanian N, Nishith SD. Effect of Yogasanas and Pranayamas on Blood Pressure, Pulse Rate and Some Respiratory Functions. Indian J Physiol Pharmacol, 1973; 17(3): 273276

Grinton SF. Respiratory Limitations in the Aging Population. South Med J, 1994; 87(5): S47-49

Harik-Khan RI, Wise RA. Determinants of Maximal Inspiratory Pressure. Am J Respir Crit Care Med, 1998; 158: 1459-1464

Higginbotham MB, Morris KG, Williams RS, Colemam RE, Cobb FR. Physiologic Basis for the Agerelated Decline in Aerobic Work Capacity. Am J Cardiol, 1986; 57(15): 1374-1379

Jakes RE, Day NE, Patel B, Khaw K, Oakes S, Lubem B, Welch A, Bingham S, Wareham NJ. Physical Inactivity is Associated with Lower Forced Expiratory Volume in 1 Second. Am J Epidemiol, 2002; 156: $139-147$

Krishnamurthy MN, Telles S. Assessing depression following two ancient Indian interventions: effects of yoga and ayurveda on older adults in a residential home. J Gerontol Nurs, 2007; 33(2): 17-23

Luby S. Hatha Yoga for total health: handbook of practical programs. Prentice-Hall. New Jersey; 1977

Mandanmoha M, Jatiya L, Udupa K, Bhavanani AB. Effect of Yoga Training on Handgrip, Respiratory Pressures and Pulmonary Function. Indian J Physiol Pharmacol, 2003; 47(4): 387-392

Manocha R, Marks GB, Kenchington P, Peters D, Salome CM. Sahaja Yoga in the Management of Moderate to Severe Asthma: a Randomized Controlled Trial. Thorax, 2002; 57: 110-115

Marek W, Marek EM, Mückenhoff K, Smith HJ, Kotschy-Lang N, Kohlhäufl M. Lung Function In Our Aging Population. Eur J Med Res, 2011; 16(3): 108-14

McKenzie DK, Allen GM, Candevia SC. Reduced Voluntary Drive to the Human Diaphragm at Low Lungs Volumes. Respir Physiol, 1996; 105: 69-76

Oken BS, Zajdel D, Kishiyama S, Flegal K, Dehen C, Haas M, Kraemer DF, Lawrence J, Leyva J. Randomized, controlled, six-month trial of yoga in healthy seniors: effects on cognition and quality of life. Altern Ther Health Med, 2006; 12(1): 40-47

Pelkonen M, Notkola I, Lakka T, Tukiainen HO, Kivinen P, Nissinen A. Delaying Decline in Pulmonary Function with Physical Activity: a 25-year follow-up. Am J Respir Crit Care Med, 2003; 168: 464-499

Ray US, Sinha B. Aerobic Capacity \& Perceived Exertion after Practice of Hatha Yogic Exercises. Indian J Med Res, 2001; 144: 215-221

Rode A, Shephard RJ. The Aging of Lung Function: Cross-sectional and Longitudinal Studies of an Inuit Community. Eur Respir J, 1994; 7(9): 1653-1659 
Rossi A, Ganassini A, Tantucci C, Grassi V. Aging and the Respiratory System. Aging (Milano), 1996; 8(3): 143-161

Teodori RM, Moreno MA, Fiore JF e Oliveira ACS. Inspiratory Muscle Stretching through postural global reduction (Abstract). Braz J Phys Ther, 2003; 7(1): 25-30

Turcic N, Zuskin E, Mustajbegovic J, Smolej-Naran N, Ivankovic D. Respiratory Symptoms, Diseases and Pulmonary Ventilatory Capacity in Persons in the Third Stage of Life. Lijec Vjesn, 2002; 124(8): 247254

Vempati RP, Telles S. Yoga-based guided relaxation reduces sympathetic activity judged from baseline levels. Psychol Rep, 2002; 90(2): 487-94

Volianitis S, Mcconnell AK, Jones, DA. Assessment of Maximum Inspiratory Pressure. Respiration, 2001; 68: $22-27$

Vyas R, Dikshit N. Effect of Meditation on Respiratory System Cardiovascular System and Lipid Profile. Indian J Physiol Pharmacol, 2002; 46(4): 487-491

Weiner P, Magadle R, Beckerman M, Weiner M, Berar-Yanay N. Specific Expiratory Muscle Training in COPD. Chest, 2003; 124: 468-473

\section{Corresponding author:}

\section{Nuno Domingos Garrido}

Department of Sport Sciences, University of Trás-os-Montes and Alto Douro, Vila Real, Portugal

Universidade de Trás-os-Montes e Alto Douro, Complexo Desportivo da UTAD, 5000-000 Vila Real,

Portugal

Phone: +351 259350877

Fax: +351 330168

E-mail: ngarrido@utad.pt 